\title{
Intramolecular Schmidt Reaction: Applications in Natural Product Synthesis
}

\author{
Erich Nyfeler and Philippe Renaud*
}

\begin{abstract}
The intramolecular Schmidt reaction was first described at the beginning of the 1990s and rapidly proved to be a powerful tool for the fast assembly of complex nitrogen-containing heterocycles. This review focuses on the application of this reaction in the synthesis of natural products and other biologically relevant compounds.
\end{abstract}

Keywords: Alkaloids · Alkyl azides · Iminium ions · Lactams · Rearrangement · Tertiary amines · Total synthesis

\section{Introduction}

The Schmidt reaction describes the reaction of carbonyl compounds, such as carboxylic acids, ketone and aldehydes, with hydrazoic acid under protic conditions resulting in the insertion of a nitrogen atom in a $\mathrm{C}-\mathrm{C}$ bond [1-6]. The reaction is also known as the Schmidt rearrangement and is closely related to the Hofmann and the Curtius rearrangements [7]. Carboxylic acid $\mathbf{1 . 1}$ reacts with hydrazoic acid to afford primary amines 1.2 (Scheme 1(a)). The reaction goes through the protonated acyl azide $\mathbf{1 . 3}$ that undergoes a rearrangement to give the protonated isocyanate 1.4. Hydrolysis of $\mathbf{1 . 4}$ affords the carboxylated amine $\mathbf{1 . 5}$ that spontaneously loses $\mathrm{CO}_{2}$ to deliver the final primary amine 1.2. The Schmidt reaction with ketones is depicted in Scheme 1(b). Treatment of ketone $\mathbf{1 . 6}$ with hydrazoic acid gives the amide 1.7. The mechanism involves the formation of the intermediate triaz-1-yn-2-ium ion 1.8 [8]. Two pathways have been proposed depending on the nature of the starting ketone. The first pathway is closely related to the Beckmann rearrange-

${ }^{\star}$ Correspondence: Prof. Dr. P. Renaud Universität Bern

Departement für Chemie und Biochemie

Freiestrasse 3

$\mathrm{CH}-3012$ Bern

Tel: : +41316314359

Fax: +41316313426

E-Mail: philippe.renaud@ioc.unibe.ch ment. Cation 1.8a loses water to give the iminodiazonium intermediate 1.9, which undergoes a 1,2 shift of an alkyl group delivering the nitrilium ion 1.10. Trapping of 1.10 by water gives the amide 1.7. In few cases, a pinacol-like mechanism involving concerted rearrangement of the tetrahedral intermediate $\mathbf{1 . 8 b}$ with concomitant loss of nitrogen has also been proposed [9][10].

A recent application of the carboxylic acid Schmidt reaction is shown in Scheme 2

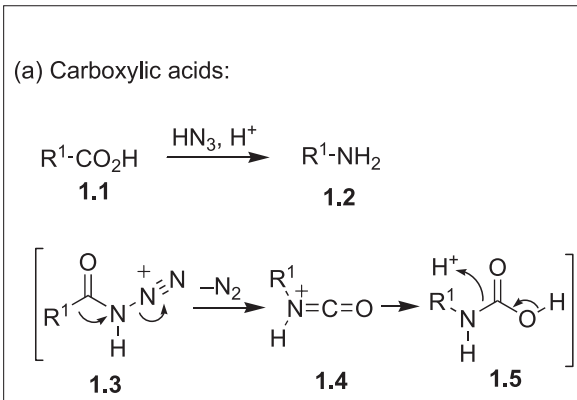

(b) Ketones:
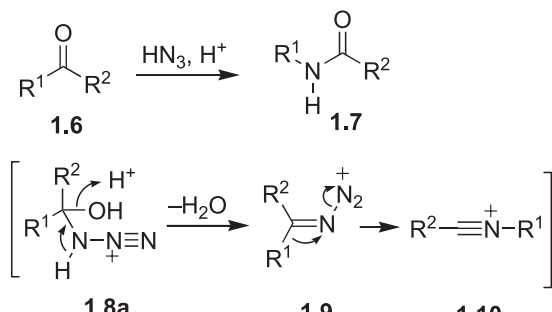

1.9

1.10

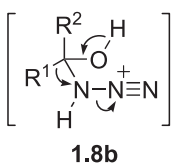

Scheme 1. Intermolecular Schmidt reactions with carboxylic acids and ketones
[11]. (+)-Camphoric acid 2.1 reacts with sodium azide in the presence of sulfuric acid to afford diamine $\mathbf{2 . 2}$ in $91 \%$ yield.

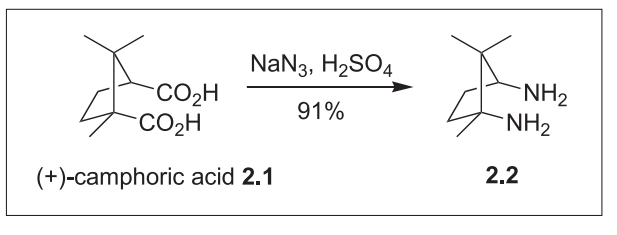

Scheme 2. Schmidt reaction for the conversion of carboxylic acids into amines [11]

The regioselectivity of the Schmidt rearrangement is controlled by a delicate balance between the two mechanisms depicted in Scheme 1(b) and by the stereochemistry of the intermediate iminodiazonium salts. For example, the reaction of bicyclic ketone 3.1 affords a 77:23 mixture of $\mathbf{3 . 2}$ and $\mathbf{3 . 3}$ in $62 \%$ yield (Scheme 3 ) [12][13]. The preferential formation of $\mathbf{3 . 2}$ results from the preferential formation of the $E$-iminodiazonium cation $E$-3.4 followed by 1,2-shift of the bridgehead substituent. The $Z$-isomer Z-3.4 affords 3.3; the product resulting from the migration of the methylene residue.

An interesting rearrangement of alkyl azides has been reported by Andrieux et al. [14]. Dihydropyrrole $\mathbf{4 . 2}$ is obtained by treatment of cyclobutanol $\mathbf{4 . 1}$ with hydrazoic acid and sulfuric acid (Scheme 4). Reduction of $\mathbf{4 . 2}$ followed by $\mathrm{N}$-methylation gives nicotine 4.3. The rearrangement involves the formation of the azide $\mathbf{4 . 4}$ followed by protonation to the aminodiazonium ion 4.5 and ring expansion via a $\mathrm{C}$ to N 1,2 alkyl shift.

Despite the synthetic usefulness of the reaction involving the formation of lactams from ketones and amines from carboxylic 


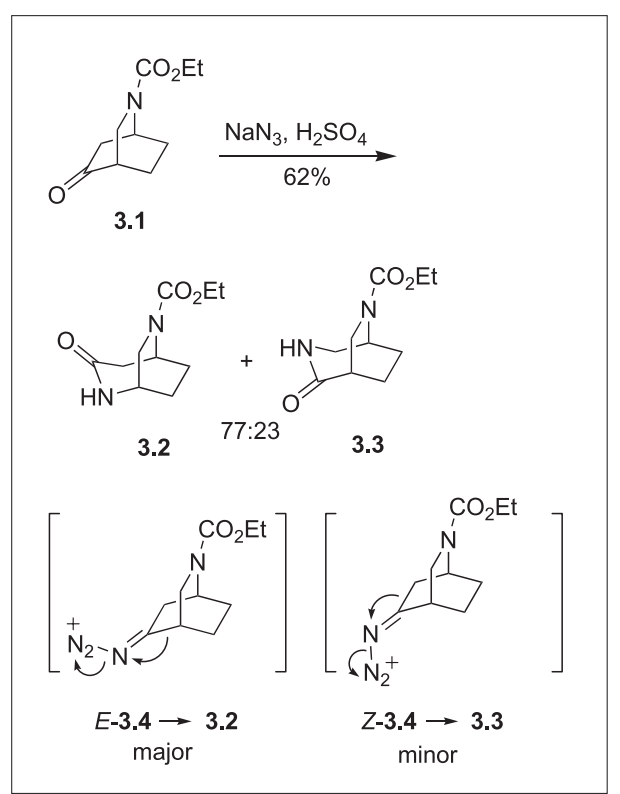

Scheme 3. Regioselectivity in the rearrangement of bridged bicyclic ketones [12]

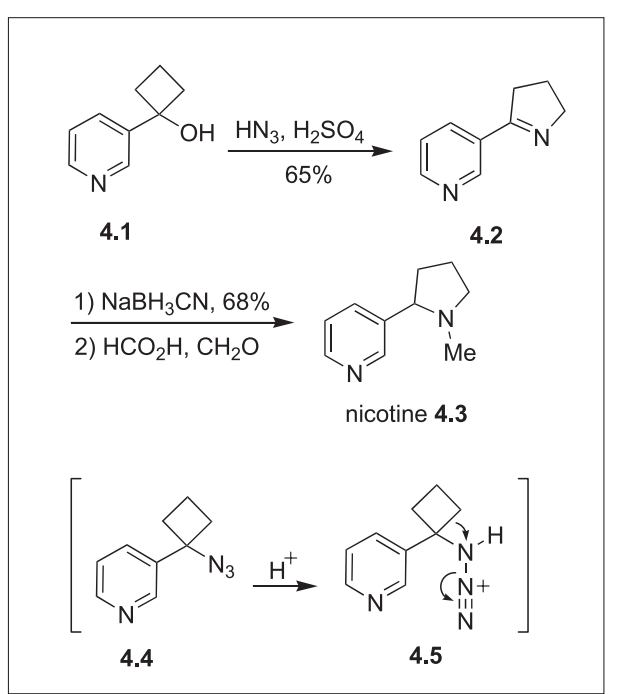

Scheme 4. Synthesis of nicotine 4.3 by Andrieux et al. [14]

acids, the intermolecular Schmidt reaction suffers from two important drawbacks. First, the strongly acidic conditions are not compatible with sensitive substrates and second, hydrazoic acid is highly toxic and explosive upon heating. For a very long time, the reaction was unjustifiably suspected to be limited to hydrazoic acid and similar reagents as azide sources. Alkyl azides were believed to be too weak as nucleophiles for this kind of rearrangements. However, in the early 1990s, Aubé and Milligan [15] and Pearson and Schkeryantz [16] independently reported the first examples of intramolecular Schmidt reaction of alkyl azides with ketones and tertiary carbocations generated from alkenes and alcohols. These pioneer works have triggered many developments and applications towards the total syntheses of natural products and other biologically relevant molecules. This review presents a selection of recent applications of the intramolecular Schmidt reaction. Results are organized according to the method used to generate the electrophilic species.

\section{Reactions of Azido Ketones}

Aubé and coworkers reported that azido ketone $\mathbf{5 . 1}$ affords the fused bicyclic lactam $\mathbf{5 . 2}$ in $83 \%$ yield under treatment with trifluoroacetic acid (Scheme 5) [15][17]. The protonated ketone $\mathbf{5 . 3}$ reacts with the azide moiety to form the azidohydrin $\mathbf{5 . 4}$ that rearranges readily to the lactam 5.2. Similar results are obtained under Lewis acid activation with titanium tetrachloride. Benzylic azides afford variable mixtures of Schmidt and Mannich reactions [18]. Intermolecular reactions between cyclic ketones and alkyl azides are possible in some cases under strong Lewis acidic conditions [19][20].

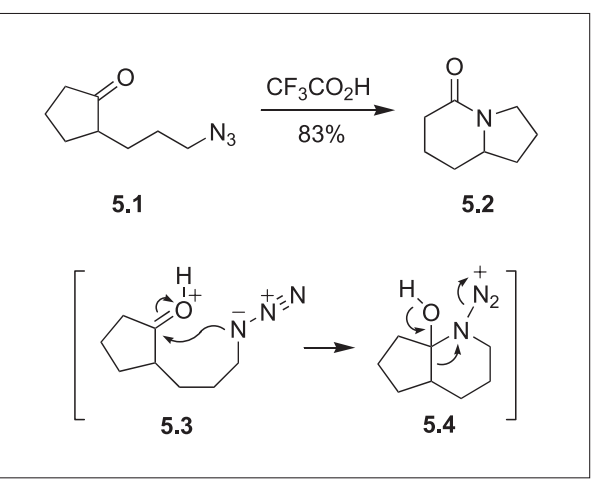

Scheme 5. Bicyclic lactam by Aubé and coworkers [15][17]

Aubé and coworkers applied the intramolecular Schmidt reaction to the total synthesis of (+)-aspidospermidine $\mathbf{6 . 5}$ (Scheme 6) [21][22]. Azido diketone $\mathbf{6 . 3}$ is obtained in ten steps starting from the easily available enone 6.1 and cyclopentanone 6.2. Intramolecular Schmidt reactions are more facile when six-membered ring azidohydrins such as $\mathbf{6 . 6}$ are involved rather than five-membered ring azidohydrins [15][17]. Therefore, diketone 6.3 reacts with complete regioselectivity under treatment with $\mathrm{TiCl}_{4}$ to deliver the tricyclic ketolactam $\mathbf{6 . 4}$ as a single product in $82 \%$ yield. Conversion of 6.4 to (+)-aspidospermidine $\mathbf{6 . 5}$ is achieved in seven steps and $43 \%$ yield.

Aubé and coworkers reported the total synthesis of indolizidine 209B [23], (-)lasubine II [24], and dendrobatid alkaloid $251 \mathrm{~F} 7.4$ using the rearrangement of an azido ketone (Scheme 7) [25][26]. Easily accessible enantioenriched carboxylic acid 7.1 is converted in eight steps and $13 \%$ yield into the azido ketone 7.2. Treatment of $\mathbf{7 . 2}$ with trifluoromethanesulfonic acid affords the tricyclic lactam 7.3 in $79 \%$ yield. Alka-

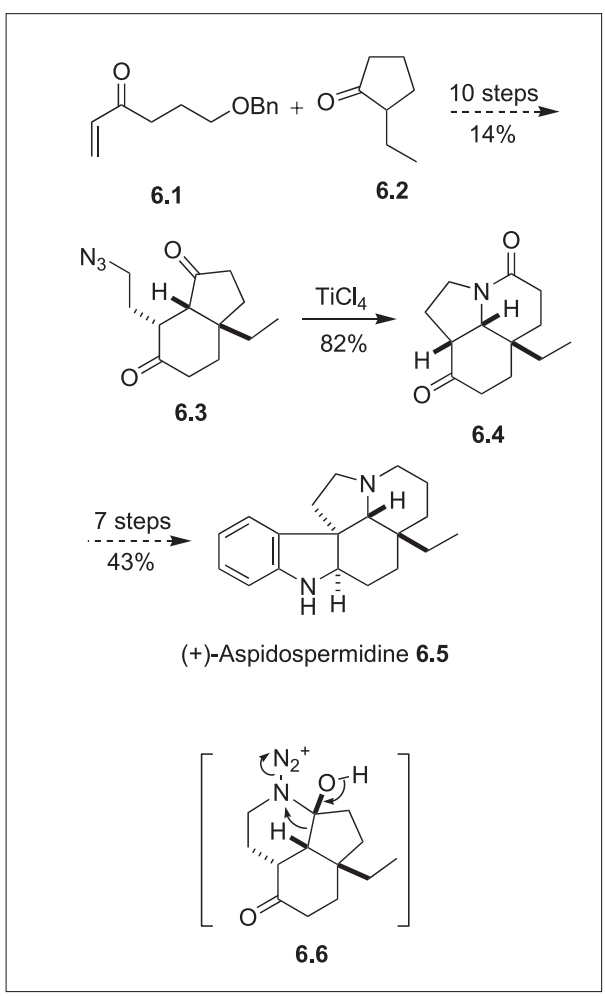

Scheme 6. Total synthesis of (+)-aspidospermidine 6.5 by Aubé and coworkers [21][22]

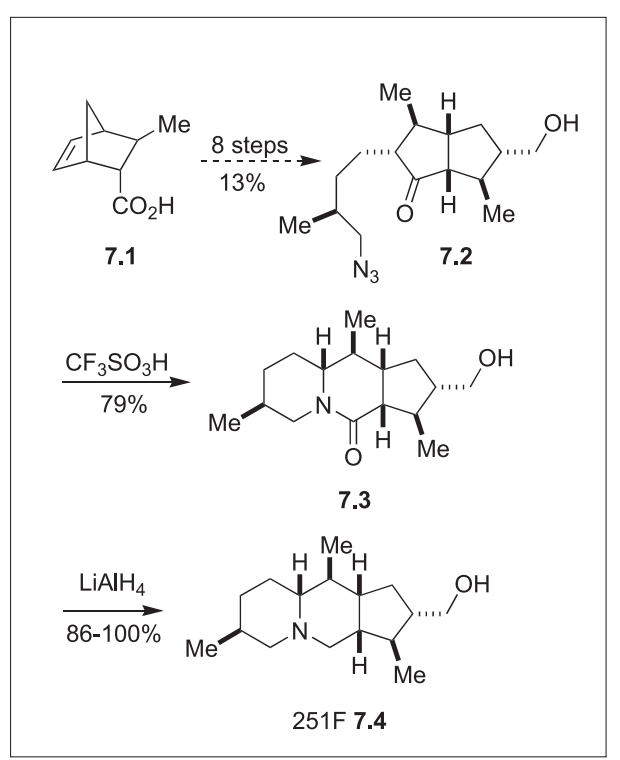

Scheme 7. Total synthesis of alkaloid 251F 7.4 by Aubé and coworkers [25][26]

loid 251F 7.4 is obtained by reduction of the lactam with lithium aluminium hydride.

The first total synthesis of (+)-sparteine 8.1, the enantiomer of naturally occurring (-)-sparteine was recently achieved by Aubé and coworkers (Scheme 8) [27]. The elegant retrosynthetic analysis consists in preparing the tetracyclic structure $\mathbf{8 . 2}$ of the target by using sequential nitrogen ring-expansion reactions on a bicyclic substrate that would ultimately be derived from the $C_{2}$-symmet- 
rical ketone 8.3. Diketone 8.3 is prepared in optically pure form via enantioselective bishydrosilylation of norbornadiene and is converted in six steps to the azido ketone 8.4, which undergoes a titanium tetrachloride promoted Schmidt reaction affording the first ring expanded lactam 8.5. The iodide 8.6 was prepared from 8.5 in five steps and $72 \%$ yield and could be easily converted to the corresponding azide. However, the second intramolecular Schmidt reaction failed, presumably due to the absence of coordination of the ketone carbonyl group by protic and Lewis acids. The second ring expansion could be achieved under neutral conditions with a variant of the photo-Beckmann rearrangement. For this purpose, the nitrone 8.7 is prepared and irradiated at $254 \mathrm{~nm}$ to give the oxaziridine $\mathbf{8 . 8}$, which undergoes the desired rearrangement to the lactam 8.9 in $76 \%$ yield. Reduction of $\mathbf{8 . 9}$ with lithium aluminium hydride gives (+)-sparteine $\mathbf{8 . 1}$ in $15 \%$ yield from norbornadione $\mathbf{8 . 3}$.
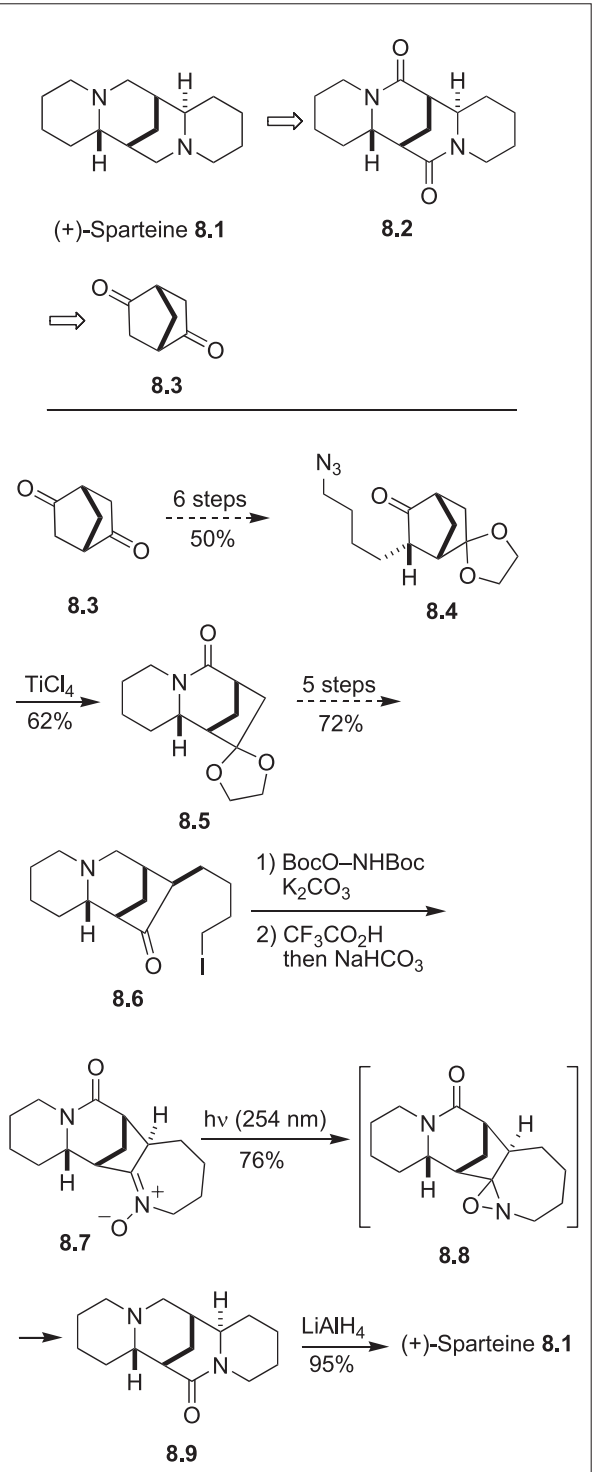

Scheme 8. The first total synthesis of (+)-sparteine 8.1 by Aubé and coworkers [27]
Desmaële and d'Angelo and coworkers applied the intramolecular Schmidt reaction of azido ketones to access the homoerythrina skeleton (Scheme 9) [28]. Starting from 6,7-dimethoxy-2-tetralone 9.1 and the iodoester 9.2, the spirocyclic azidoketone 9.3 is prepared in five steps. Under treatment with trifluoroacetic acid, 9.3 leads to the lactam 9.4 in $85 \%$ yield as a single product. Reduction with lithium aluminium hydride gives 3-demethoxy-1,2-dihydrocomosidine 9.5 .

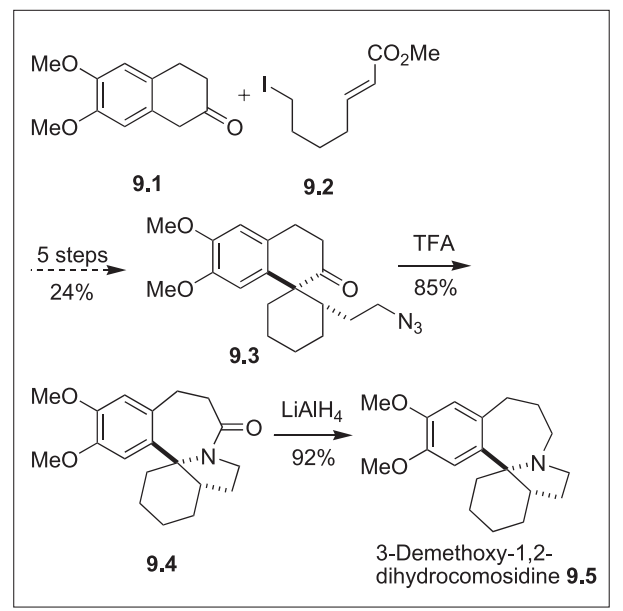

Scheme 9. Total synthesis of homoerythrina alkaloids by Desmaële and d'Angelo and coworkers [28]

Since both Diels-Alder and intramolecular Schmidt reactions are catalyzed by Lewis acids, it is very attractive to develop a domino process involving these two reac- tions. The first example of such a sequential process was developed by the Aubé group and is based on an intramolecular Diels-Alder reaction followed by an intramolecular Schmidt reaction. It was applied to a formal synthesis of $( \pm$ )-stenine $\mathbf{1 0 . 6}$ (Scheme 10) [29]. The azidodiene $\mathbf{1 0 . 1}$ is treated with methylaluminium dichloride to afford a mixture of the three lactams 10.2, 10.3, and 10.4. The major product $\mathbf{1 0 . 2}$ is easily converted to $\mathbf{1 0 . 5}$, an advanced intermediate for the synthesis of $( \pm)$-stenine 10.6. The regioselective formation of $\mathbf{1 0 . 2}$ during the Schmidt reaction is rationalized assuming an antiperiplanar $\mathrm{C}$ to $\mathrm{N}$ bond migration from the intermediate azidohydrin $\mathbf{1 0 . 7}$ possessing an equatorial diazonium leaving group (migrating bonds are shown in bold in structure 10.7).

A further development of this domino strategy involving an intermolecular Diels-Alder reaction and an intramolecular Schmidt reaction was recently published by the same group. This approach is illustrated by the preparation of the fused bicyclic ketoamide $\mathbf{1 1 . 2}$ starting from the readily available azido diene 11.1. Reaction of $\mathbf{1 1 . 1}$ with methyl vinyl ketone in the presence of tin tetrachloride afforded the rearranged lactam $\mathbf{1 1 . 2}$ in $60 \%$ yield [30] via the Diels-Alder adduct $\mathbf{1 1 . 3}$ (Scheme 11).

This procedure has been applied for a second very elegant and short total synthesis of $( \pm)$-stenine $\mathbf{1 0 . 6}$ from the diene 12.1 (available in three steps from a known $\beta$-ketophosphonate) and cyclohexenone (Scheme 12) [31]. The complex tricyclic
Scheme 10. Synthesis of $( \pm)$-stenine 10.6 according to Aubé and coworkers via a domino reaction involving intramolecular DielsAlder and Schmidt reactions [29] $(\mathrm{LA}=$ Lewis acid).
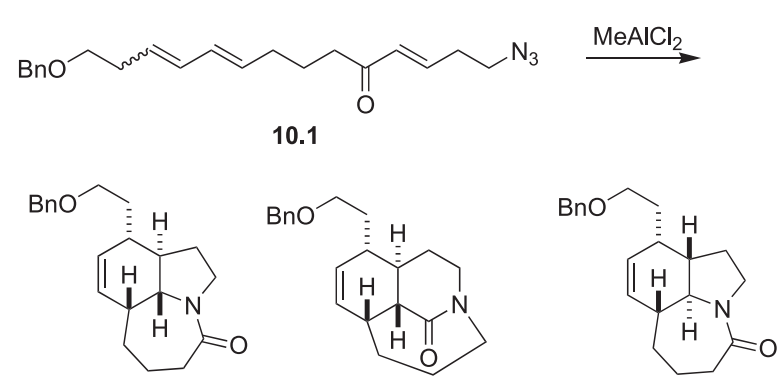

$10.2(43 \%)$

$10.3(24 \%)$

$10.4(12 \%)$
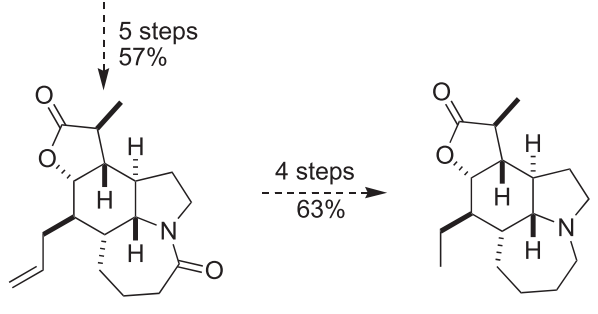

10.5

(士)-Stenine 10.6

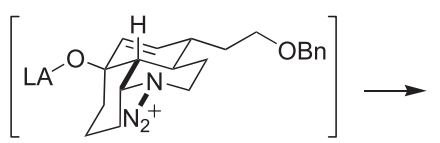




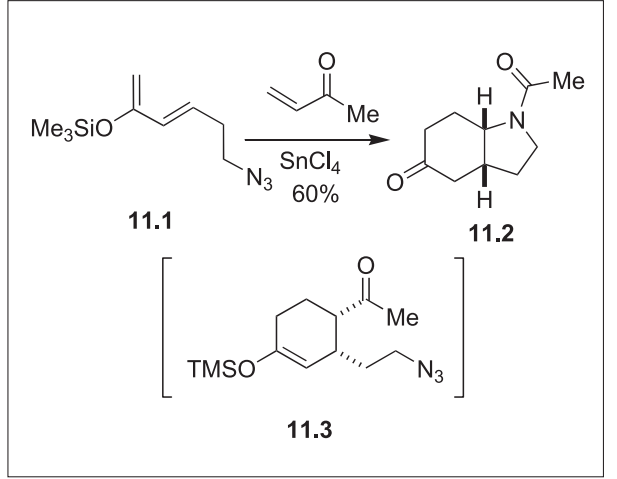

Scheme 11. Domino process involving an intermolecular Diels-Alder reaction and an intramolecular Schmidt reaction by the Aubé group [30]

core structure $\mathbf{1 2 . 2}$ was obtained in 53\% yield using tin tetrachloride as a catalyst. The synthesis of racemic stenine $\mathbf{1 0 . 6}$ was subsequently achieved in five steps with an overall yield of $16 \%$.

\section{Reactions of Azido Ketals, Hemiketals, and Enol Ethers}

Aubé and coworkers have shown that azido ketals are converted to lactams via a mechanism closely related to the Schmidt reaction of azido ketones. For example, azido ketal $\mathbf{1 3 . 1}$ gives $\mathbf{1 3 . 2}$ in $94 \%$ yield under treatment with trimethylsilyl triflate and $\mathrm{NaI}$ [32] (Scheme 13). The reaction involves the formation of the oxonium ion $\mathbf{1 3 . 3}$ that reacts with the azide to form 13.4, which undergoes a rearrangement to the methoxyiminium ion 13.5. Finally, demethylation of $\mathbf{1 3 . 5}$ with $\mathrm{NaI}$ affords the bicyclic lactam 13.2. Similar results are obtained by using methyl enol ethers. With these substrates, simple protonation generates the required oxonium ions. For example, enol ether $\mathbf{1 3 . 6}$ affords lactam $\mathbf{1 3 . 7}$ in $89 \%$ yield when treated with trifluoroacetic acid.

The group of Aubé reported an efficient nitrogen ring-expansion process based on the intermolecular reaction of a ketone with an azido alcohol in the presence of a

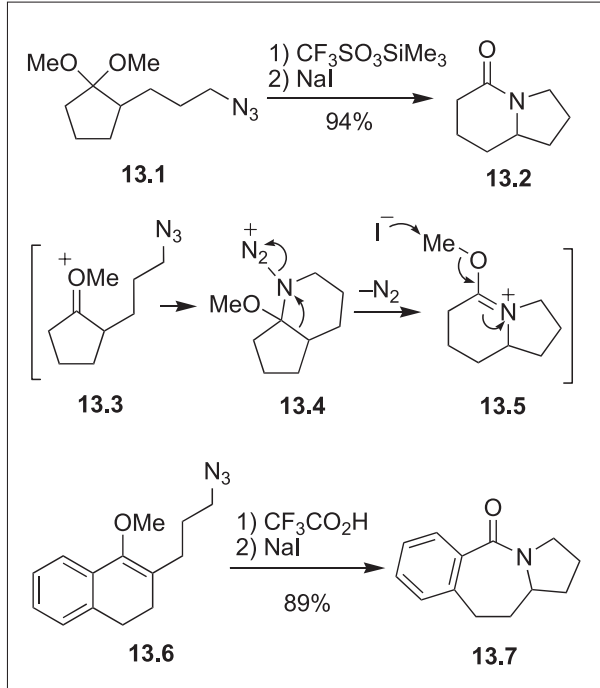

Scheme 13. Synthesis of lactams starting from azido ketals and azido enol ethers by Aubé and coworkers [32]

Lewis acid [33-36]. The reaction is facilitated by in situ hemiketal formation. By using a chiral azido alcohol, it is possible to develop an asymmetric version of this reaction allowing the desymmetrization of cyclohexanone derivatives [37]. A typical example is shown in Scheme 14 [38][39]. 4-tert-Butylcyclohexanone $\mathbf{1 4 . 1}$ reacts with the chiral azido alcohol $\mathbf{1 4 . 2}$ in the presence of $\mathrm{BF}_{3} \cdot \mathrm{OEt}_{2}$ to afford the amide 14.3 in quantitative yield and excellent diastereoselectivity (dr 95:5). The reaction involves the formation of the hemiketal 14.4 that gives under Lewis acid catalysis the oxonium ion 14.5. Nucleophilic addition of the azide to the oxonium ion affords the aminodiazonium intermediate 14.6. The nitrogen atom occupies an equatorial position relative to the cyclohexanone ring [40]. In the reactive conformation of the tetrahydrooxazine, the phenyl ring occupies the more stable equatorial position. In order to allow an antiperiplanar migration of an adjacent alkyl group, the $\mathrm{N}_{2}{ }^{+}$leaving group should occupy an axial position (migrating bonds are shown in bold in structure 14.6).

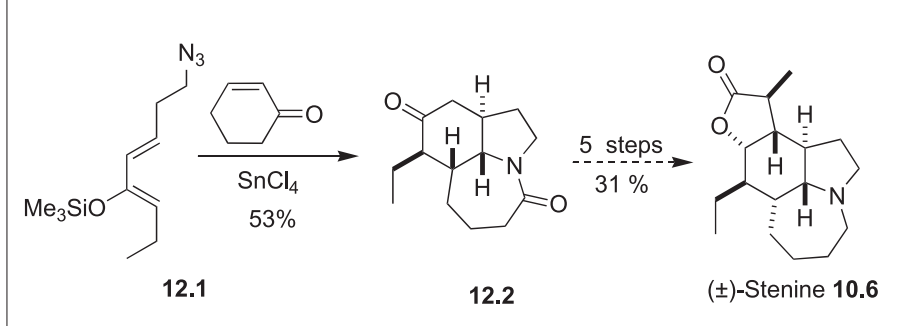

Scheme 12. Total synthesis of ( \pm )-stenine 10.6 using a domino intermolecular Diels-Alder reaction-intramolecular Schmidt reaction process by Aubé and coworkers [31]

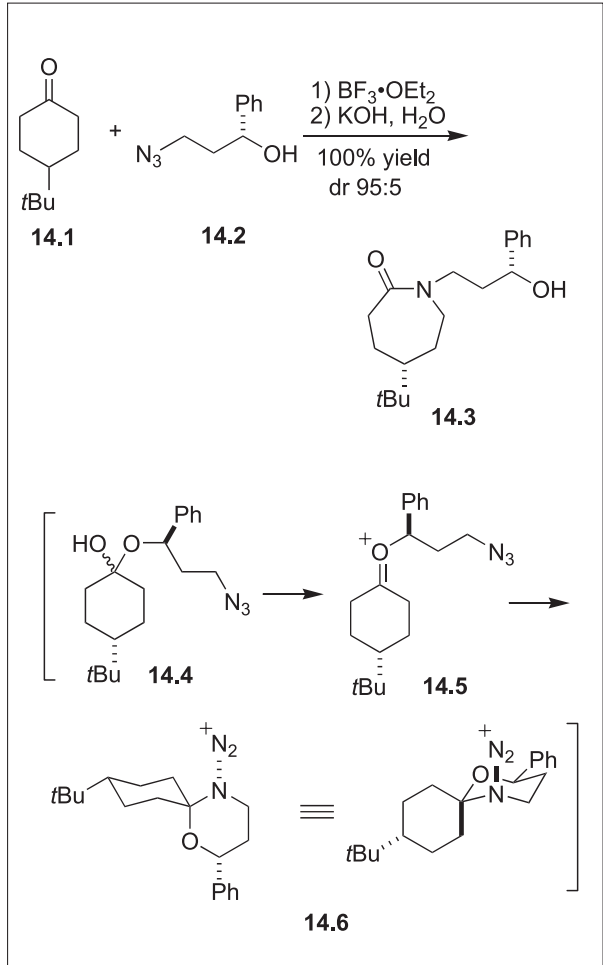

Scheme 14. Asymmetric Schmidt reaction with azido alcohols by Aubé and coworkers [39]

\section{Reactions of Azido Alkenes}

Pearson and Fang have investigated the reaction of azides with carbocations generated from alkenes. Besides intermolecular reactions [41][42], several examples of intramolecular processes are described [43]. The azido alkene $\mathbf{1 5 . 1}$ is easily converted to the bicyclic alkene $\mathbf{1 5 . 2}$ by treatment with trifluoromethanesulfonic acid [16] (Scheme 15). The reaction involves protonation of the olefin to produce the benzylic cation 15.3, which is captured by the azide to form the aminodiazonium ion 15.4. Migration of an adjacent alkyl group leads to the cation $\mathbf{1 5 . 5}$ and finally to the olefin $\mathbf{1 5 . 2}$ after loss of a proton

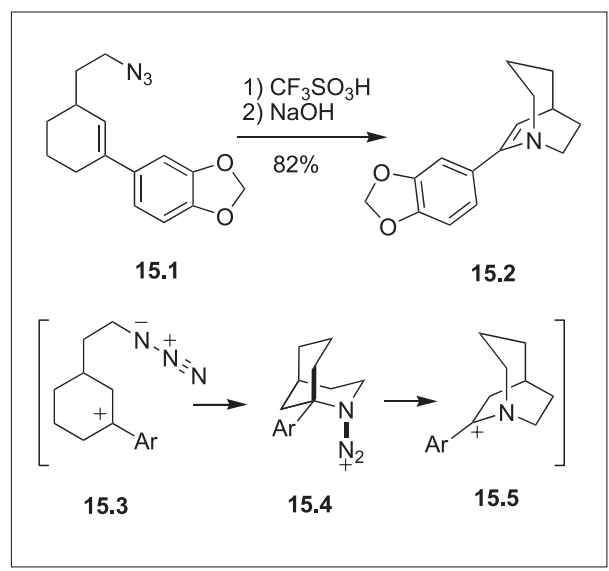

Scheme 15. Preparation of a bridged bicyclic amine from an azidoalkene by Pearson and Schkeryantz [16] 
The synthesis of indolizidines from methylenecyclopentane derivatives was also examined (Scheme 16). Treatment of the azido alkene $\mathbf{1 6 . 1}$ with trifluoromethanesulfonic acid followed by reduction of the intermediate iminium salt with $\mathrm{NaBH}_{4}$ gives the expected product 16.2 together with its regioisomer $\mathbf{1 6 . 3}$ in $71 \%$ yield [44]. This unexpected lack of regioselectivity indicates that the reaction is not going through cyclization of the carbocation $\mathbf{1 6 . 4}$ leading to the aminodiazonium ion $\mathbf{1 6 . 5}$ followed by rearrangement to the iminium 16.6. In fact, a 1,2 hydride shift converting the initial carbocation $\mathbf{1 6 . 4}$ into $\mathbf{1 6 . 7}$ is taking place. Cyclization of the azido cation $\mathbf{1 6 . 7}$ affords the spirocyclic aminodiazonium salt 16.8, which undergoes a non-selective alkyl group migration. The lack of regioselectivity is surprising since it was expected that migration of the most substituted alkyl group should prevail. This result is best explained by a stereoelectronic control of the regioselectivity. The aminodiazonium ion 16.8 exists as two rapidly interconverting conformers 16.8a and 16.8b that undergo a selective antiperiplanar migration of the adjacent alkyl group. Finally, the two iminium ions $\mathbf{1 6 . 9}$ and $\mathbf{1 6 . 1 0}$ are reduced by sodium borohydride to the corresponding indolizidines $\mathbf{1 6 . 2}$ and 16.3.
Pearson and Fang observed the preferential migration of aromatic residues relative to aliphatic ones [45]. This selective migration has been used for the formal total synthesis of ( \pm )-gephyrotoxin 17.7 (Scheme 17). The bromo azide 17.2, obtained in nine steps and $45 \%$ yield from commercially available indanone 17.1, affords tricyclic bromo amines upon treatment with trifluoromethanesulfonic acid followed by in situ reduction of the iminium ion intermediates 17.3 and 17.4 with L-Selectride ${ }^{\circledR}$ (= lithium tri-sec-butylborohydride). The crude bromides are converted into the corresponding alcohols $\mathbf{1 7 . 5}(45 \%)$ and $\mathbf{1 7 . 6}(10 \%)$ by treatment with $\mathrm{Bu}_{4} \mathrm{NaOAc}$ and reduction of the acetate by $\mathrm{LiAlH}_{4}$. The amino alcohol $\mathbf{1 7 . 5}$ has already been further reduced by Ito $e t$ al. [46] to an advanced intermediate in Kishi and coworkers' total synthesis of gephyrotoxin [47].

A mercury-promoted intramolecular Schmidt reaction, developed by Pearson et $a l$., has solved the problem of regioselectivity due to the rearrangement of carbocations discussed above (Scheme 16). For instance, under protic conditions, (methylenecyclohexyl)propyl azide $\mathbf{1 8 . 1}$ gives a 1:1 mixture of the regioisomers $\mathbf{1 8 . 2}$ and 18.3. The mercuric perchlorate promoted reaction affords $\mathbf{1 8 . 2}$ as a single regioisomer [48] (Scheme 18). This

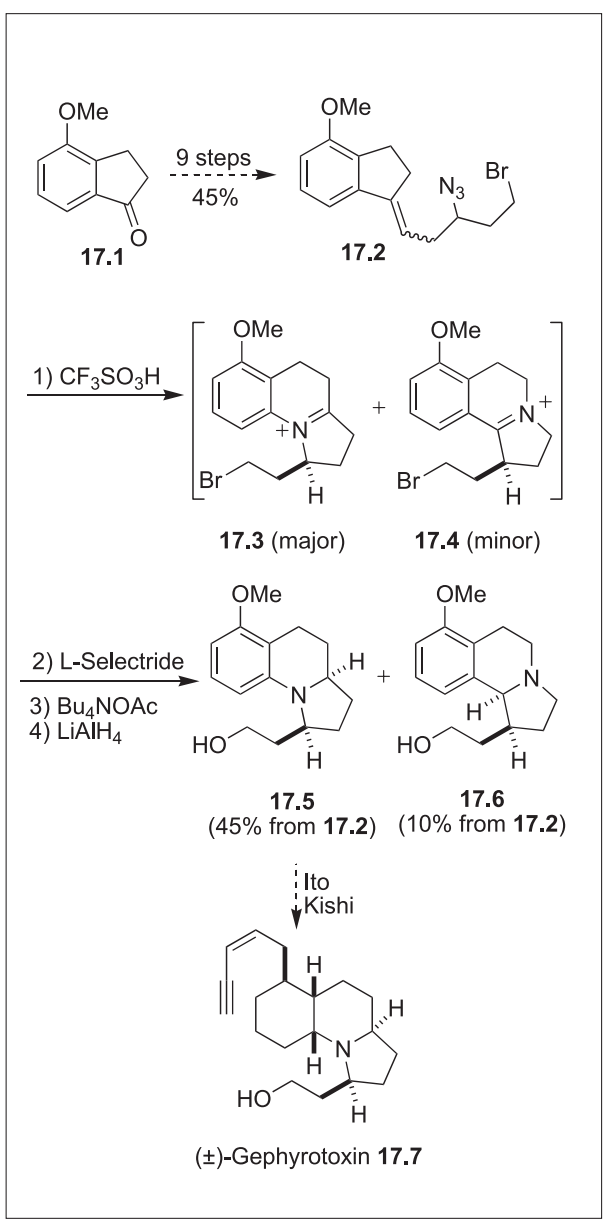

Scheme 17. Formal total synthesis of $( \pm$ )gephyrotoxin 17.7 by Pearson and Fang [45]

process begins with the formation of the mercuronium ion $\mathbf{1 8 . 4}$ or its equivalent that reacts with the azide to produce the aminodiazonium ion $\mathbf{1 8 . 5}$ without cationic rearrangement. Selective migration of the adjacent alkyl group affords the iminium 18.6 that is reduced by sodium borohydride to 18.2. Interestingly, migration of mercurioalkyl groups seems to be inhibited. For instance, conversion of $\mathbf{1 8 . 7}$ to $\mathbf{1 8 . 8}$ results from a selective migration of the aryl group. No migration of the mercurioalkyl group is observed although migration of the corresponding alkyl group is observed when the rearrangement proceeds under protic conditions.

\section{Reactions of Azido Alcohols}

Pearson and coworkers have shown that azido alcohols can serve as starting materials for the Schmidt rearrangement [44]. The benzylic tertiary azido alcohol $\mathbf{1 9 . 1}$ gives indolizidine 19.2, a potential dopamine analogue, as a single regioisomer in $68 \%$ yield upon treatment with tin tetrachloride followed by reduction with $\mathrm{BH}_{3} \cdot \mathrm{SMe}_{2}$ (Scheme 19) [49]. This transformation involves a stabilized benzylic carbocation 19.3 that does not rearrange as previously discussed for 16.4 (see Scheme 16). 


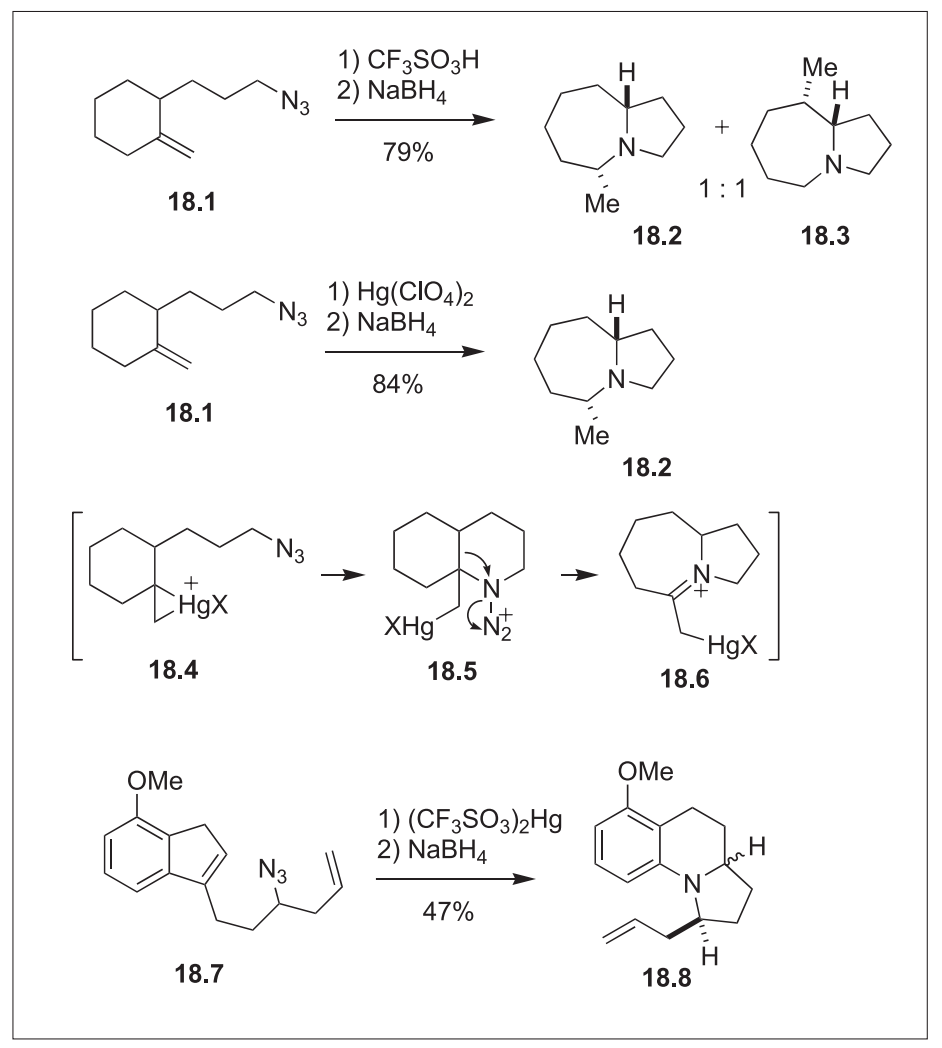

Scheme 18. Mercury(II) promoted Schmidt reaction of azido alkenes by Pearson et al. [48]

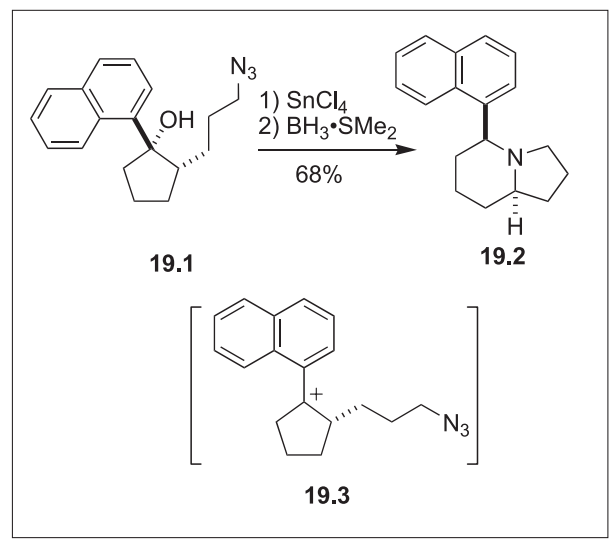

Scheme 19. Regioselective preparation of the dopamine analogue 19.2 by Pearson [49]

Carbocations generated from tertiary azido alkanols undergo a 1,2 hydride shift before reacting with the azide (as shown for the azido alkenes in Scheme 16). This is illustrated by the conversion of $\mathbf{2 0 . 1}$ into a 1.3:1 mixture of indolizidine 167B $\mathbf{2 0 . 2}$ and its regioisomer $\mathbf{2 0 . 3}$ in $35 \%$ yield upon treatment with trifluoromethanesulfonic acid (Scheme 20).

An elegant solution to the regioselectivity problem was proposed for the synthesis of ( \pm )-indolizidine 167B 20.2 (Scheme 21) [44]. Exposing the cyclic azido alcohol 21.2, available in six steps from 1,5-dicyclooctane 21.1, to trifluoromethanesulfonic acid followed by reduction with sodium borohydride affords ( \pm )-indolizidine 167B 20.2 (Scheme 20) [44]. Intramolecular nucleophilic addi-

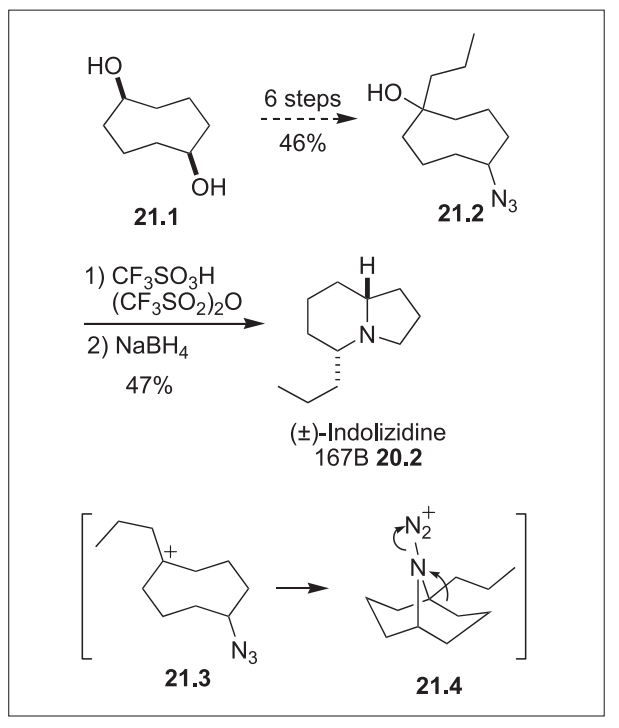

Scheme 21. Regioselective synthesis of indolizidine 167B 20.2 by Pearson and Gallagher [44]

tion of the azide to the carbocation converts 21.3 into the symmetrical bridged bicyclic aminodiazonium ion 21.4. 1,2-Alkyl shift with extrusion of $\mathrm{N}_{2}$ affords an iminum ion that is stereoselectively reduced anti to the propyl chain to deliver $\mathbf{2 0 . 2}$.

\section{Reaction of Azido Epoxides}

Baskaran and coworkers have investigated the intramolecular Schmidt reaction starting from azido epoxides [50][51]. For instance, treatment of the optically active epoxide 22.1 with ethylaluminium dichloride followed by sodium borohydride afforded indolizidine $\mathbf{2 2 . 2}$ as a single regioisomer (Scheme 22). This is remarkable since proton promoted reactions starting from either alkenes (Scheme 16) or tertiary alcohols (Scheme 20) lead to mixtures of regioisomers due to rearrangement of the initially formed carbocation. Indolizidine 22.2 is easily converted into (-)-indolizidine 167B 20.2 and 209D 22.3 via tosylation of the alcohol followed by reaction with $\mathrm{R}_{2} \mathrm{Cu}(\mathrm{CN}) \mathrm{MgBr}\left(\mathrm{R}=\mathrm{Et}, \mathrm{nC}_{5} \mathrm{H}_{11}\right)$ [52].

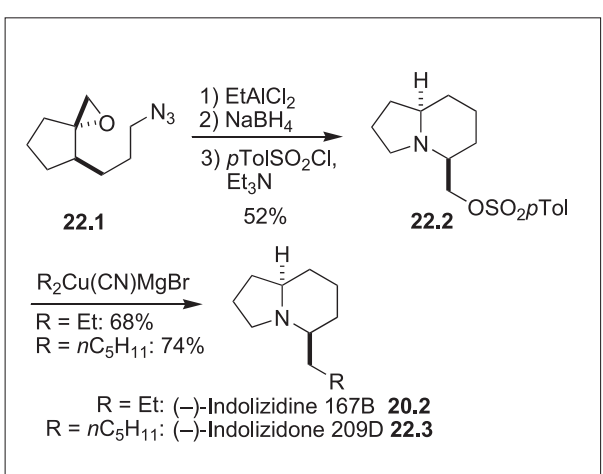

Scheme 22. Synthesis of (-)-indolizidine 167B 20.2 and 209D 22.3 by Reddy and Baskaran [51]

An interesting tandem reaction involving a cationic cyclization followed by a Schmidt reaction has been reported [50] (Scheme 23). Treatment of the epoxide 23.1, easily prepared from geraniol, with ethylaluminium dichloride followed by reduction with sodium borohydride gives azepine 23.2. The aminodiazonium ion $\mathbf{2 3 . 3}$ was proposed as a plausible intermediate that undergoes a regioselective migration of the alkyl group anti to the $\mathrm{N}_{2}$ leaving group.

Another cascade reaction involving an intramolecular Schmidt reaction was reported by Murphy (Scheme 24) [53]. Treatment of the azido epoxide $\mathbf{2 4 . 1}$ with $\mathrm{BF}_{3} \cdot \mathrm{OEt}_{2}$ gives the tricyclic amino ketone $\mathbf{2 4 . 2}$ in $94 \%$ yield. The reaction involves the formation of the aminodiazonium ion $\mathbf{2 4 . 3}$ followed by an aryl migration leading 


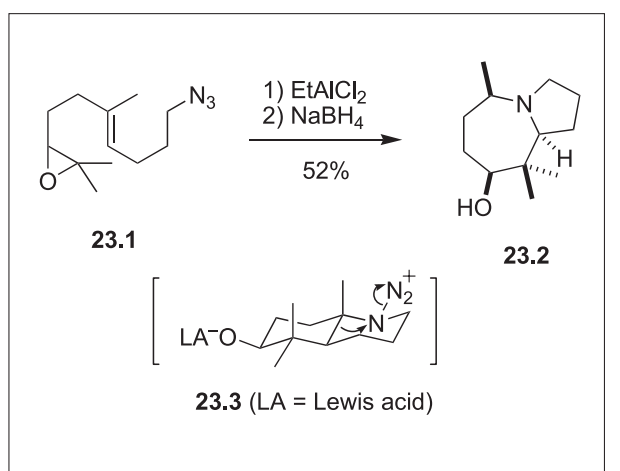

Scheme 23. Synthesis of diazepine $\mathbf{2 3 . 2}$ from geraniol by Baskaran and coworkers [50]

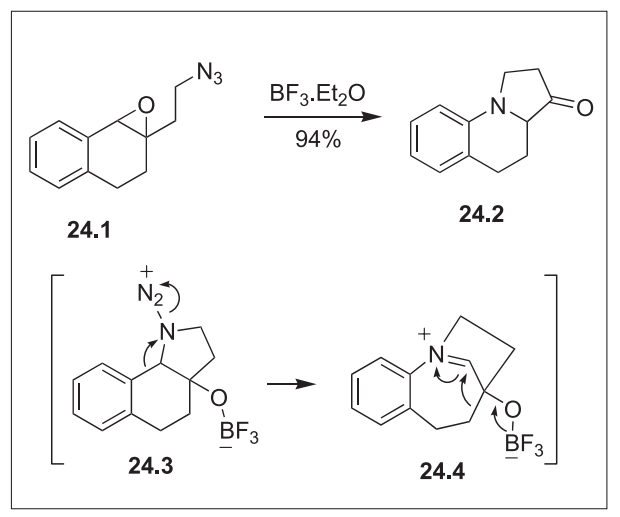

Scheme 24. Cascade reaction starting from the azido epoxide 24.1 by Murphy and coworkers [53]

to the iminium ion $\mathbf{2 4 . 4}$ which eventually rearranges (1,2 alkyl shift) to the desired arylamino ketone $\mathbf{2 4 . 2}$.

\section{Boyer and Related Reactions}

Mechanistically akin to the Schmidt reaction, the Boyer reaction refers to the reaction of 2-azidoalcohols with aldehydes leading to 4,5-dihydro-1,3-oxazole and 5,6dihydro-4H-1,3-oxazine [54]. For example, benzaldehyde 25.1 reacts with 1-azido-2propanol $\mathbf{2 5 . 2}$ in the presence of sulfuric acid to give 5-methyl-2-phenyl-4,5-dihydro1,3-oxazole 25.3 in $80 \%$ yield (Scheme 25 ). This reaction does not involve the migration of an alkyl but the elimination of a proton from aminodiazonium ion $\mathbf{2 5 . 4}$ instead.

In their work on the estrone skeleton, Schneider and coworkers have reported a similar reaction of the azido alcohol 26.1 with benzaldehyde catalyzed by $\mathrm{BF}_{3} \cdot \mathrm{OEt}_{2}$ (Scheme 26) [55]. Dihydrooxazine 26.2 is isolated in $82 \%$ yield.

Magnus and Matthews developed a closely related process for the synthesis of a model system related to the total synthesis of tetrahydroquinoline alkaloids such as saframycin A, lemonomycin, and ecteinascidin 743 [56] (Scheme 27). In this reaction,

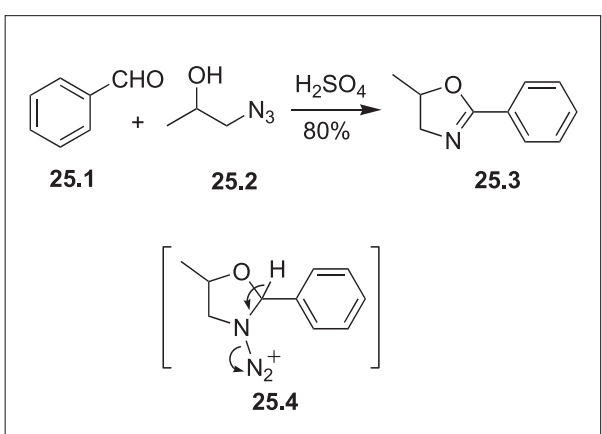

Scheme 25. Preparation of 5-methyl-2-phenyl4,5-dihydro-1,3-oxazole according to Boyer and Hamer [54]

the tricyclic lactam 27.3 is prepared from the azido sulfide 27.1 by treatment with $\mathrm{N}$-chlorosucciminide and tin tetrachloride followed by hydrolysis of the intermediate thiophenylimino ether 27.2. The reaction involves the intramolecular addition of the azide to a sulfonium ion leading to the aminodiazonium ion 27.4.

Molina et al. reported that the azido alkene $\mathbf{2 8 . 1}$ gives the pyrroline $\mathbf{2 8 . 2}$ in $\mathbf{7 2 \%}$ yield upon treatment with trifluoromethanesulfonic acid followed by triethylamine (Scheme 28) [57]. The reaction goes through the benzylic carbocation 28.3 that cyclizes to the aminodiazonium ion $\mathbf{2 8 . 4}$.

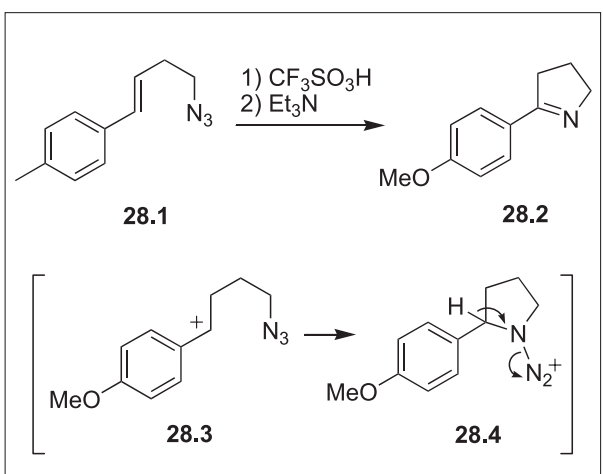

Scheme 28. Preparation of the pyrroline 28.2 by cyclization of an azido alkene by Molina et al. [57]

Recently, Toste and coworkers described a gold(I)-catalyzed method for the preparation of heavily substituted pyrroles from homopropargylic azides [58]. A typical example is shown in Scheme 29. The homopropargylic azide $\mathbf{2 9 . 1}$ gives the pyrrole $\mathbf{2 9 . 2}$ in $82 \%$ yield in the presence of a gold(I) catalyst. The mechanism presumably involves an initial gold promoted endo-dig cyclization (depicted in 29.3) leading to 29.4. Subsequent loss of dinitrogen produces the cationic intermediate 29.5. A formal 1,2 shift regenerates the gold(I) catalyst and produces the $2 \mathrm{H}$-pyrrole 29.6 that tautomerizes to the $1 H$-pyrrole $\mathbf{2 9 . 2}$.

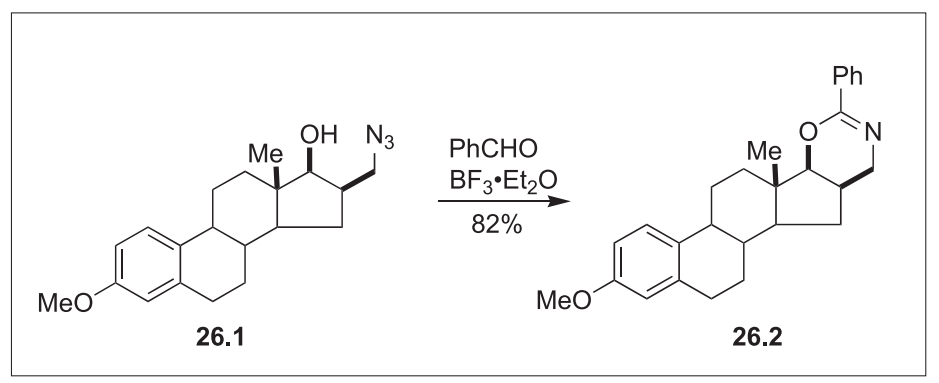

Scheme 26. Synthesis of dihydrooxazine 26.2 via a Lewis acid catalyzed Boyer reaction by Schneider et al. [55]

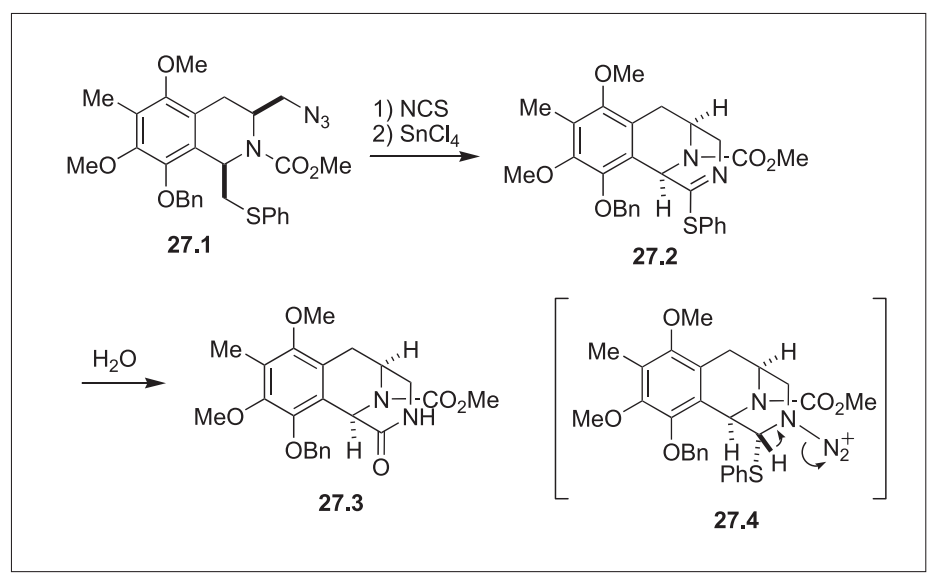

Scheme 27. Preparation of the lactam 27.3 from an azido sulfide by Magnus and Matthews [56] 


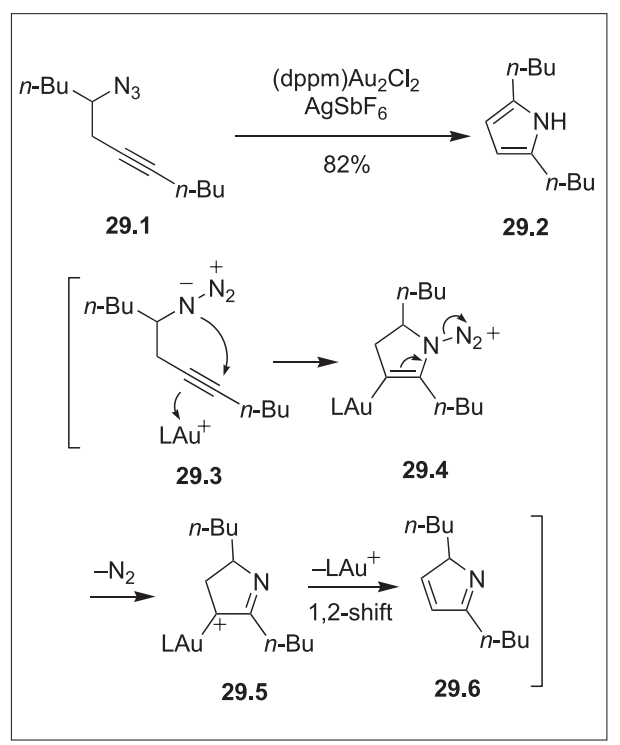

Scheme 29. Gold(I)-catalyzed preparation of pyrroles from homopropargylic azides by Toste and coworkers [58]

The preparation of lactams from azido aldehydes represents an interesting extension of the Boyer reaction. Horton and coworkers described the cyclization of the azido aldehyde $\mathbf{3 0 . 1}$ to D-xylonolactam $\mathbf{3 0 . 2}$ in $84 \%$ yield (Scheme 30) [59]. The reaction is promoted by titanium tetrachloride and involves the formation of the intermediate azidohydrin 30.3. Hirai et al. applied this reaction for the synthesis of pyrrolidinone derivatives as illustrated by the conversion of $\mathbf{3 0 . 4}$ to $\mathbf{3 0 . 5}$ in $65 \%$ yield (Scheme 30 ) [60].

$$
\text { }
$$$$
30.2
$$

$$
\left[{ }_{\mathrm{OBz}}\right.
$$

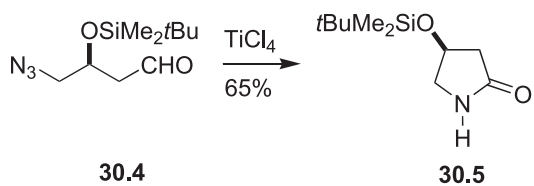

Scheme 30. Preparation of lactams from azido aldehydes by Horton and coworkers [59] and Hirai and coworkers [60]

\section{Rearrangement of Azido Boranes}

The intermolecular reaction of organoboranes with azides was first described by Brown et al. [61][62] and represents a useful method for the amination of organoboranes [63]. Its mechanism is closely related to the Schmidt reaction. An intramolecular version was reported by Evans and Weber in the synthesis of the cyclic hexapeptide echinocandin D [64] (Scheme 31). The azido alkene $\mathbf{3 1 . 1}$ was converted to $\mathbf{3 1 . 2}$ via the intermediate aminodiazonium $\mathbf{3 1 . 3}$ (migrating bonds are shown in bold in structure 31.3). This reaction was further examined by Sabol and coworkers [65] and Salmon and Carboni [66]. More recently, the Lebreton group reported an elegant synthesis of tobacco's pyrrolidine and piperidine alkaloids using this rearrangement as the key step. For example, the synthesis of nicotine 4.3 involves the conversion of the azido alkene 31.4 into the pyrrolidine 31.5 via hydroboration with dicyclohexylcatecholborane [67].

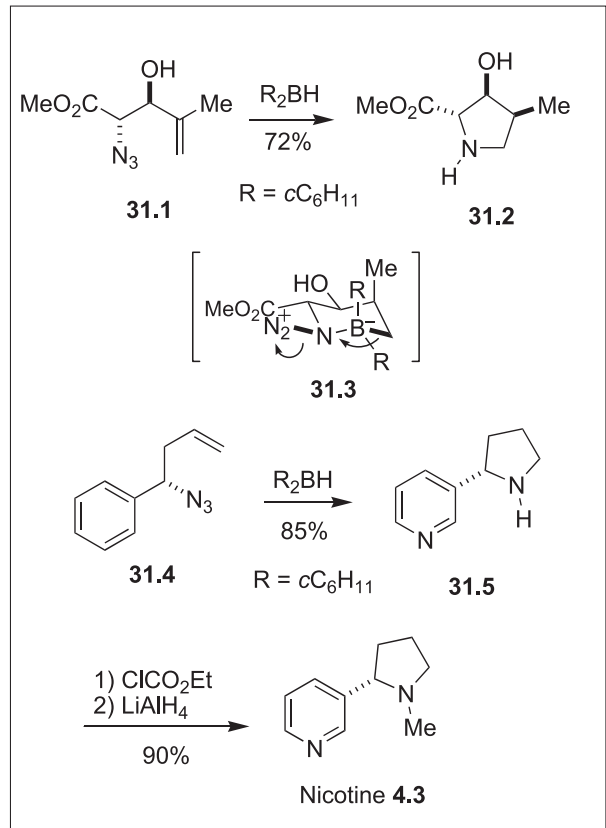

Scheme 31. Preparation of the trisubstituted pyrrolidine 31.2 (building block for the synthesis of echinocandin D) by Evans and Weber [64] and nicotine 4.3 by Lebreton and coworkers [67]

\section{Conclusion}

The intramolecular Schmidt reactions and related rearrangements are very attractive processes that can be used for the synthesis of $\mathrm{N}$-containing heterocycles commonly found in alkaloids. The use of Lewis acids to promote the Schmidt reaction has considerably extended its scope. Further developments to achieve better control of the regio- and stereoselectivity are still required.

\section{Acknowledgements}

We thank the Swiss National Science Foundation (project 20-103627) and the State Secretariat for Education and Research (COST Action D28, project C03.0047) for financial support.

Received: April 18, 2006

[1] H. Wolff, Org. React. 1946, 3, 307.

[2] P.A.S. Smith, in 'Molecular Rearrangements', Ed. P. de Mayo, Wiley, New York, 1963, p. 457.

[3] R.A. Abramovich, E.P. Kyba, in 'The Chemistry of the Azido Group', Ed. S. Patai, Wiley, London, 1971, p. 221.

[4] E.P. Kyba, in 'Azides and Nitrenes: Reactivity and Utility', Ed. E.F.V. Scriven, Academic, Orlando, 1984, p. 2.

[5] E.F.V. Scriven, K. Turnbull, Chem. Rev. 1988, 88, 297.

[6] S. Lang, J.A. Murphy, Chem. Soc. Rev. 2006, 35, 146.

[7] K.F. Schmidt, Angew. Chem. 1923, 36, 511.

[8] P.A.S. Smith, J. Am. Chem. Soc. 1948, 70, 320.

[9] R.D. Bach, G.J. Wolber, J. Org. Chem. 1982, 47, 239.

[10] L.E. Fikes, H. Shechter, J. Org. Chem. 1979, 44, 741

[11] K. He, Z. Zhou, L. Wang, K. Li, G. Zhao, Q. Zhou, C. Tang, Tetrahedron 2004, 60, 10505.

[12] G.R. Krow, S.W. Szczepanski, J.Y. Kim, N. Liu, A. Sheikh, Y. Xiao, J. Yuan, J. Org. Chem. 1999, 64, 1254.

[13] G.R. Krow, O.H. Cheung, Z. Hu, Y.B. Lee, J. Org. Chem. 1996, 61, 5574.

[14] G.F. Alberici, J. Andrieux, G. Adam, M.M. Plat, Tetrahedron Lett. 1983, 24, 1937.

[15] J. Aubé, G.L. Milligan, J. Am. Chem. Soc. 1991, 113, 8965.

[16] W.H. Pearson, J.M. Schkeryantz, Tetrahedron Lett. 1992, 33, 5291.

[17] G.L. Milligan, C.J. Mossmann, J. Aubé, J. Am. Chem. Soc. 1995, 117, 10449.

[18] A. Wrobleski, J. Aubé, J. Org. Chem. 2001, 66, 886 .

[19] J. Aubé, G.L. Milligan, C.J. Mossmann, J. Org. Chem. 1992, 57, 1635.

[20] P. Desai, K. Schildknegt, K.A. Agrios, C. Mossman, G.L. Milligan, J. Aubé, J. Am. Chem. Soc. 2000, 122, 7226.

[21] R. Iyengar, K. Schildknegt, J. Aubé, Org. Lett. 2000, 2, 1625.

[22] R. Iyengar, K. Schildknegt, M. Morton, J. Aubé, J. Org. Chem. 2005, 70, 10645.

[23] J. Aubé, P.S. Rafferty, G.L. Milligan, Heterocycles 1993, 35, 1141.

[24] V. Gracias, Y.B. Zeng, P. Desai, J. Aubé, Org. Lett. 2003, 5, 4999.

[25] A. Wrobleski, K. Sahasrabudhe, J. Aubé, J. Am. Chem. Soc. 2002, 124, 9974.

[26] A. Wrobleski, K. Sahasrabudhe, J. Aubé, J. Am. Chem. Soc. 2004, 126, 5475.

[27] B.T. Smith, J.A. Wendt, J. Aubé, Org. Lett. 2002, 4, 2577. 
[28] M.-A. Le Dréau, D. Desmaële, F. Dumas, J. d'Angelo, J. Org. Chem. 1993, 58, 2933.

[29] J.E. Golden, J. Aubé, Angew. Chem. Int. Ed. 2002, 41, 4316.

[30] Y. Zeng, S.D. Reddy, E. Hirt, J. Aubé, Org. Lett. 2004, 6, 4993.

[31] Y. Zeng, J. Aubé, J. Am. Chem. Soc. 2005, $127,15712$.

[32] C.J. Mossmann, J. Aubé, Tetrahedron 1996, 52, 3403.

[33] V. Gracias, G.L. Milligan, J. Aubé, J. Am. Chem. Soc. 1995, 117, 8047.

[34] V. Gracias, G.L. Milligan, J. Aubé, J. Org. Chem. 1996, 61, 10.

[35] J.E. Forsee, J. Aubé, J. Org. Chem. 1999, $64,4381$.

[36] B.T. Smith, V. Gracias, J. Aubé, J. Org. Chem. 2000, 65, 3771.

[37] C.E. Katz, J. Aubé, J. Am. Chem. Soc. 2003, 125, 13948.

[38] K. Furness, J. Aubé, Org. Lett. 1999, 3, 495.

[39] K. Sahasrabudhe, V. Gracias, K. Furness, B.T. Smith, C.E. Katz, S.D. Reddy, J.Aubé, J. Am. Chem. Soc. 2003, 125, 7914.

[40] N.D. Hewlett, J. Aubé, J.L. RadkiewiczPoutsma, J. Org. Chem. 2004, 69, 3439.

[41] W.H. Pearson, W.K. Fang, Isr. J. Chem. 1997, 37, 39.

[42] W.H. Pearson, W.K. Fang, J. Org. Chem. 1995, 60, 4960.

[43] W.H. Pearson, J. Heterocycl. Chem. 1996, 33, 1489.

[44] W.H. Pearson, R. Walavalkar, J.M. Schkeryantz, W.F. Fang, J.D. Blickensdorf, J. Am. Chem. Soc. 1993, 115, 10183.

[45] W.H. Pearson, W.-K. Fang, J. Org. Chem. 2000, 65, 7158

[46] Y. Ito, E. Nakajo, M. Nakatsuka, T. Saegusa, Tetrahedron Lett. 1983, 24, 2881.

[47] R. Fujimoto, Y. Kishi, J.F. Blount, J. Am. Chem. Soc. 1980, 102, 7154.
[48] W.H. Pearson, D.A. Hutta, W.K. Fang, $J$. Org. Chem. 2000, 65, 8326.

[49] W.H. Pearson, B.M. Gallagher, Tetrahedron 1996, 52, 12039.

[50] P.G. Reddy, B. Varghese, S. Baskaran, Org. Lett. 2003, 5, 583.

[51] P.G. Reddy, S. Baskaran, J. Org. Chem. 2004, 69, 3093.

[52] P.G. Reddy, M.G. Sankar, S. Baskaran, Tetrahedron Lett. 2005, 46, 4559.

[53] S. Lang, A.R.K. Kennedy, J.A. Murphy, A.H. Payne, Org. Lett. 2003, 5, 3655.

[54] J.H. Boyer, J. Hamer, J. Am. Chem. Soc. 1955, 77, 951.

[55] G. Schneider, J. Wölfling, A. Hajnal, Synlett 2002, 7, 1077.

[56] P.D. Magnus, K.S. Matthews, Abstracts of Papers of the American Chemical Society 2004, 227, U170.

[57] P. Molina, J. Alcántara, C. Lopéz-Leonardo, Synlett 1995, 363

[58] D.J. Gorin, N.R. Davis, F.D. Toste, J. Am. Chem. Soc. 2005, 127, 11260.

[59] P. Norris, D. Horton, B.R. Levine, Tetrahedron Lett. 1995, 36, 7811.

[60] K. Hirai, K. Kobayashi, S. Kobayashi, Synlett 1999, 4, 909.

[61] H.C. Brown, M.M. Midland, A.B. Levy, J. Am. Chem. Soc. 1973, 95, 2394.

[62] H.C. Brown, M.M. Midland, A.B. Levy, J. Am. Chem. Soc. 1972, 94, 2114.

[63] B. Carboni, M. Vaultier, Bull. Soc. Chim. Fr. 1995, 132, 1003.

[64] D.A. Evans, A.E. Weber, J. Am. Chem. Soc. 1987, 109, 7151.

[65] P.P. Waid, G.A. Flynn, E.W. Huber, J.S. Sabol, Tetrahedron Lett. 1996, 37, 4091.

[66] A. Salmon, B. Carboni, J. Organomet. Chem. 1998, 567, 31.

[67] F.X. Felpin, S. Girard, G. Vo-Thanh, R.J. Robins, J. Villieras, J. Lebreton, J. Org. Chem. 2001, 66, 6305. 